\title{
HPLC-DAD Method for Investigating Pantoprazole for its Stress-Dependent Degradation by Photolysis and Oxidation
}

\author{
Mohammad Al Bratty ${ }^{1}$, Neelaveni Thangavel ${ }^{1}$, Ramalingam Peraman ${ }^{2 *}$, Vinod Kumar ${ }^{3}$, \\ Padmanabha Reddy ${ }^{3}$, Krishna Veni Nagappan ${ }^{4}$ and Hassan Al Hazmi ${ }^{1}$ \\ 'Department of Pharmaceutical Chemistry, Faculty of Pharmacy, Jazan University, Jazan, P.O. Box 114, KSA 45142 \\ RERDS-Centre for Pharmaceutical Research, Raghavendra Institute of Pharmaceutical Education and Research Campus, \\ Anantapuramu, Andhra Pradesh, India 515721 \\ ${ }^{3}$ Department of Pharmaceutical Analysis, Raghavendra Institute of Pharmaceutical Education and Research - Autonomous, \\ Anantapuramu, Andhra Pradesh, India 515721.
}

${ }^{4}$ Department of Pharmaceutical Analysis, JSS College of Pharmacy, Ooty [A Constituent College - JSS Academy of Higher Education \& Research], The Nilgiris, Tamil Nadu, India 643001.

Received: 14 Sep 2019; accepted: 03 Dec 2019

\begin{abstract}
A reversed-phased high-performance liquid chromatography-diode-array detection (HPLC-DAD) method has been developed for investigating the stress-dependent degradation of pantoprazole (PTZ) by a photolytic and oxidative mechanism. The developed method separated PTZ from its degradation products on a $\mathrm{C}_{18}$ column with a mobile phase consisted of methanol and water $(60: 40, v / v ; \mathrm{pH} 3.0)$ at a flow rate of $1 \mathrm{~mL} / \mathrm{min}$. The linear regression coefficient of 0.9995 was obtained for a concentration range from 5 to $25 \mu \mathrm{g} / \mathrm{mL}$. The $\%$ relative standard deviation for repeatability and intermediate precision were below $0.5 \%$ and $1.5 \%$, respectively, while the sensitivity of the method was demonstrated by a limit of detection value of $0.25 \mu \mathrm{g} / \mathrm{mL}$. The stress sample analyses for PTZ results revealed the formation of a total of 18 degradation products, and out of them, 9 degradation products were common for both photolytic and oxidative degradations. Further, the oxidation by azobisisobutyronitrile produced the highest number of degradation products (11 impurities), 3 of which are more hydrophobic than PTZ. In photolytic degradation, 8 and 7 degradation products were observed with UV radiation and sunlight exposure, respectively. Furthermore, the degradation of pantoprazole sodium injection formulation was carried out under the same stress conditions, and it revealed the formation of 3 common impurities under both stress conditions, but other impurities were not detected in the formulations. Finally, 3 common impurities formed in formulations of PTZ injections, viz., sulfone, $\mathrm{N}$-oxide, and $\mathrm{N}$-oxide sulfone impurities, were identified by spike analyses.
\end{abstract}

Keywords: RP-HPLC, pantoprazole, photolytic, oxidative, stability indicating

\section{Introduction}

Controlling degradation impurities in pharmaceutical products is still a challenging task among the pharmaceutical scientists. The International Conference on Harmonization (ICH)-recommended forced degradation procedure is used to identify the potential degradation products, which are formed during stress degradation, but actually formed in a drug substance or in its product under long-term storage or under accelerated storage conditions [1]. This information helps scientists for designing appropriate measures to minimize the expected impurities in the life cycle of drug products. Stress testing (forced degradation study) has become an important fundamental regulatory requirement for drug development and approval process [2]. It provides evidence regarding the impact of various environmental factors on the quality of drug substances or drug products in real-time and is the scientific basis to recommend the storage condition and package technology for a dosage form [3]. In pharmaceutical analytical research, the design of stress conditions is the crucial and the

*Author for correspondence: RERDS-Centre for Pharmaceutical Research, Raghavendra Institute of Pharmaceutical Education and Research [RIPER] Campus, Anantapuramu, Andhra Pradesh, India 515721; drramalingamp@gmail.com; Phone: +919581294478. preliminary step in conducting stability studies for drug product, because it reveals the intrinsic mechanism of drug decomposition, along with the information pertaining to $\%$ degradation and number of impurities, which are expected in the life cycle of the drug product [4]. In the literature, we could see that forced degradation studies were conducted using one chemical reagent or one stress inducer in each type of stress condition including acid and base hydrolyses, oxidation, and photolysis. It's our opinion that the degradation study with a single stress inducer or stress agent for each stress may not reveal the complete degradation profile of a drug substance, because the intrinsic pathway of chemical decomposition depends on the type of catalyst or reagent or stress inducer used. As per the ICH Q1 guidelines, photolytic degradation is very important in stress studies for drug substance, which concludes the need for conducting a photo-stability study for their formulations. We felt that unlike the reported and existing routine stress study procedure, there is a need for conducting a forced degradation study for a drug substance using different stress inducers under each stress condition. The result of this type of study will reveal the complete stress degradation profile of a drug substance, along with the information on stress-dependent or stress-specific degradation products for a drug substance or products.

This is an open-access article distributed under the terms of the Creative Commons Attribution-NonCommercial 4.0 International License (https://creativecommons.org/licenses/by-nc/4.0/), which permits unrestricted use, distribution, and reproduction in any medium for non-commercial purposes, provided the original author and source are credited, a link to the CC License is provided, and changes - if any - are indicated. 


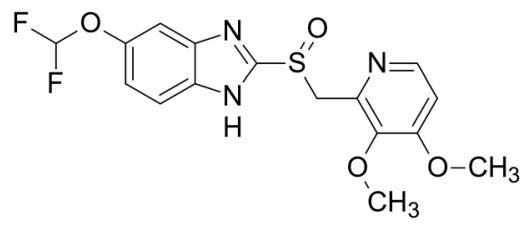

a) Pantoprazole

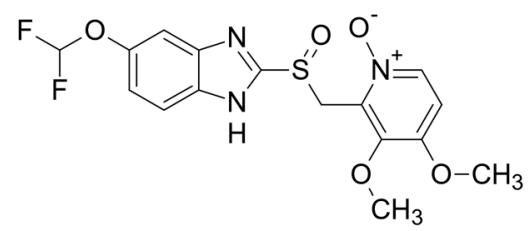

c) Pantoprazole Impurity - N-oxide

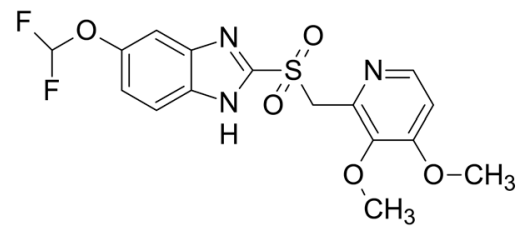

b) Pantoprazole Impurity - Sulfone derivative

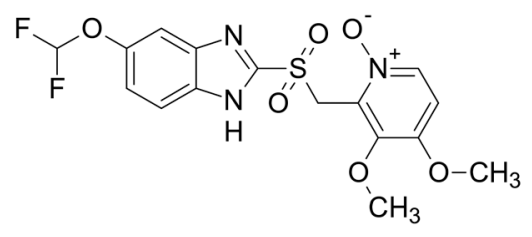

d) Pantoprazole Impurity - N-oxide of Sulfone derivative

Figure 1. Chemical structure of pantoprazole and its sulfone and N-oxide impurities

It is well known that the knowledge of photolytic and oxidative degradation of a drug substance or a drug product is very essential for defining the storage condition and packaging technology. In this study, pantoprazole (PTZ) was chosen as an exemplar drug in this study (Figure 1) due to its instability under light and oxygen. PTZ is a proton pump inhibitor, chemically known as 5-(difluoromethoxy)-2- $[[(3,4$ dimethoxy-2-pyridinyl) methyl] sulfinyl] - $1 H$-benzimidazole (Figure 1). It is available as a delayed-release tablet $(40 \mathrm{mg}$ and $20 \mathrm{mg}$ ), injectable powder, and oral suspension for the treatment of conditions like ulcer, oesophagitis, and heartburn, difficulty in swallowing, persistent cough, and esophagus cancer. The literature revealed the various analytical reports based on UV spectrophotometry [5-7], high-performance liquid chromatography (HPLC) [8-10], liquid chromatography-tandem mass spectrometry (LC-MS/MS) [11-13], high-performance thin-layer chromatography (HPTLC) [14, 15], and voltammetry [16] methods are available for the assay of PTZ in pharmaceutical dosage forms and in biological fluids. In connection with forced degradation studies, few stability-indicating HPLC methods $[5,17,18]$ have been reported for the determination of PTZ in the presence of degradation products. Among these studies, Gupta et al. [17] reported 5 impurities from oxidative degradation but had not carried out photolysis. There are methods on the identification of process impurities [18] and degradation products [19] for PTZ by reversed-phase HPLC (RP-HPLC) methods. Besides, several analytical studies are available for PTZ in the literature, but those methods are not realistic and logically unacceptable, and they lack any one or the other stability-indicating method requirements, such as the following: a) complete degradation profile, b) appropriateness of stress employed, c) specificity, d) acceptable system suitability parameters, e) incomplete validation, and f) risk of method failure.

In connection with the stability studies on pantoprazole formulations, it was evident that EDTA free pantoprazole injections are unstable. For this reason, several preformulation investigations have been conducted to enhance the stability of pantoprazole including sodium salt formation, enteric coating, packaging technology, nano-formulation and lyophilisation. However, the lyophilized pantoprazole sodium injection demonstrated acceptable stability data when compared to the PTZ drug substance. Therefore, the analytical research on the stability of pantoprazole still is continuing interest [20-23]. Consequently, the objective of this study was focused on establishing a stress-dependent degradation profile of PTZ using oxidative and photolytic degradations. This approach would be beneficial for choosing an appropriate stress inducer in stability testing protocol and also affords complete data on stress-dependent degradation profile of the drug. Thus, in this work, we employed 4 oxidative and 3 photolytic stress conditions under controlled atmosphere to pantoprazole substance and its pantoprazole sodium injection formulation. At the end of the stress sample analyses, we also attempted to identify the major impurities detected in formulation by spike analysis.

\section{Experimental}

2.1. Materials and Methods. Pantoprazole (PTZ) reference drug (99.98\%) was kindly provided as a gift sample by Walksman Salman Pharmaceuticals Pvt. Ltd., Anantapur, AP (India). Pantoprazole sodium injection powder formulation was purchased from the local community pharmacy through research authorization letter. HPLC-grade solvents and ARgrade reagents were procured from Merck, Mumbai, India.

2.2. Equipment. The HPLC analyses for method development process, forced degradation studies, and method validation were performed on an Agilent LC 1200 system equipped with a binary pump plus, a Rheodyne injector $(20 \mu \mathrm{L})$, and a photodiode-array detector (PDA). The signal was monitored using Ezchrome Elite software at different wavelengths using $3 \mathrm{D}$ mixed view. PTZ was separated on an Inertsil ODS $\mathrm{C}_{18}$ column $(250 \mathrm{~mm} \times 4.6 \mathrm{~mm}$ i.d., $5-\mu \mathrm{m}$ particle size). Validated micropipette and the glasswares used were calibrated to fulfill the requirement for class A-type as per the Indian Pharmacopeia. The light source used in the photo-stability study was calibrated with quinine actinometry as per the ICH Q1B guidelines.

2.3. Optimization of Chromatographic Conditions. Initially, the LC system was checked for its performance qualification. Then, the mobile phase was prepared according to the requirement of the LC technique, which involved degassing and filtration for each method trial. The contents of the mobile phase and samples were filtered through a $0.45-$ $\mu \mathrm{m}$ membrane filter and degassed using a sonication process before analysis. The PTZ at $15 \mu \mathrm{g} / \mathrm{mL}$ was used in the method development process. The initial method optimization procedure has begun with $10 \%$ aqueous with $\mathrm{pH} 3.5$ and $90 \%$ methanol. The retention was about $3.9 \mathrm{~min}$; thus, the retention behavior of PTZ on the $\mathrm{C}_{18}$ column was assured. Therefore, the experimental trials were continued by varying the \% aqueous and $\mathrm{pH}$ to achieve acceptable retention time $(>8 \mathrm{~min})$, tailing factor $(<2.0)$, and theoretical plate $(>3000)$. The various experimental trials performed in the optimization 
Table 1. Optimization of RP-HPLC method condition for the study of stress-dependent degradation of pantoprazole

\begin{tabular}{lccccc}
\hline S. No. & $\begin{array}{c}\text { Mobile phase } \\
\text { composition }\end{array}$ & $\mathrm{pH}$ & $\begin{array}{c}\text { Retention time } \\
\left(t_{\mathrm{R}}\right) \text { in min }\end{array}$ & $\begin{array}{c}\text { Tailing } \\
\text { factor }\end{array}$ & $\begin{array}{c}\text { Theoretical } \\
\text { plates }\end{array}$ \\
\hline 1 & $\begin{array}{c}\text { Methanol-water } \\
(80: 20, v / v) \\
2\end{array}$ & 3.5 & 3.967 & 1.3101 & 2852 \\
& $\begin{array}{c}\text { Methanol-water } \\
(70: 30, v / v) \\
3\end{array}$ & 3.5 & 5.593 & 1.5312 & 4774 \\
4 & $\begin{array}{c}\text { Methanol-water } \\
(65: 35, v / v) \\
\text { Methanol-water } \\
(60: 40, v / v)\end{array}$ & 3.0 & 7.380 & 1.2650 & 4862 \\
& & 10.373 & 1.2540 & 4852 \\
\hline
\end{tabular}

process are shown in Table 1 . The system suitability parameters of the developed method are shown in Table 2. Thus, the optimized mobile phase consisted of methanol and water at a ratio of 60:40 $(\mathrm{v} / \mathrm{v})$ and was eluted at a flow rate of $1 \mathrm{~mL} / \mathrm{min}$ and at an ambient column temperature. The photodiode array detection (PDA) wavelength was set to $290 \mathrm{~nm}$ for PTZ for detections (Figure 2) and 230, 245, 254, 310, and $330 \mathrm{~nm}$ for stress samples. However, the PDA-3D mixed view program was used in the monitoring of UV absorbing impurities.

Table 2. Optimized conditions and SST parameters for the developed RP-HPLC method for PTZ

\begin{tabular}{lcc}
\hline S. No. & Parameters & Description $/$ results \\
\hline 1 & Chromatographic column & Inertsil ODS C18 column \\
2 & Column description & $250 \mathrm{~mm} \times 4.6 \mathrm{~mm}$ i.d., $5 \mu \mathrm{m}$ \\
3 & Column temperature & Ambient \\
4 & $\%$ Aqueous & $40 \%(\mathrm{pH} 3.0$ with OPA $)$ \\
5 & Organic phase & Methanol \\
6 & Flow rate & $1.0 \mathrm{~mL} / \mathrm{min}$ \\
7 & Detection & $289 \mathrm{~nm}(\mathrm{PDA})$ \\
8 & Run time & $20 \mathrm{~min}$ \\
9 & Injection volume & $20 \mu \mathrm{L}$ \\
10 & Injection mode & Manual \\
11 & Elution mode & Isocratic \\
12 & Retention time & $10.3 \pm 0.1 \mathrm{~min}$ \\
13 & Resolution & More than 5 \\
14 & Repeatability & $0.45(\% \mathrm{RSD})$ \\
15 & Theoretical plates & $>4500$ \\
\hline
\end{tabular}

2.4. Preparation of Calibration Standards of PTZ. Ten milligrams of PTZ was accurately weighed and dissolved in $10 \mathrm{~mL}$ of HPLC-grade methanol and made up to the volume with water to get primary stock $(1000 \mu \mathrm{g} / \mathrm{mL})$. From these, respective aliquots were diluted using the mobile phase to achieve different concentrations of $5,10,15,20$, and $25 \mu \mathrm{g} /$ $\mathrm{mL}$ (Calibration Standard solutions). All standards were injected under the optimized chromatographic conditions in triplicate, and the mean value was used to construct the linearity plot. The regression coefficient was used to validate the concentration range, and the regression equation was used to quantify PTZ (Table 3 ).

2.5. Stress Degradation Studies of PTZ. The degradation of the PTZ drug substance was performed under various oxidative and photolytic stress conditions at room temperature. Each degradation study is detailed in the following section. Degradation was induced to a PTZ drug substance at a concentration of $1000 \mu \mathrm{g} / \mathrm{mL}$. The suitable aliquot was made up to the volume $10 \mathrm{~mL}$ to get a test sample concentration of $15 \mu \mathrm{g} / \mathrm{mL}$. The overlay of chromatograms of blank, control, and test stress sample injections was used to identify the formed degradation product. The \% degradation was calculated based on peak areas of the degraded PTZ sample and PTZ standard (Control). The \% degradation of $15-20 \%$ was considered as the endpoint for sample analyses. Results of degradation data of PTZ for all stress conditions were consolidated and are shown in Table 3.

2.6. Stress Degradation Studies of Pantoprazole Sodium Injection. Degradation study for PTZ sodium injection powder was carried out under the same conditions as adopted for the PTZ drug substance. The PTZ injection powder was appropriately weighed and used to prepare a concentration of $1000 \mu \mathrm{g} / \mathrm{mL}$ with suitable stress inducers. At the end of stress duration, the suitable aliquot was diluted to the volume of $10 \mathrm{~mL}$ to achieve a concentration of $15 \mu \mathrm{g} / \mathrm{mL}$. The impurities detected in the chromatogram for the PTZ injection formulation are presented in Table 3.

2.7. Oxidative Stress Degradation. The oxidative stress degradation study was carried out using different oxidative

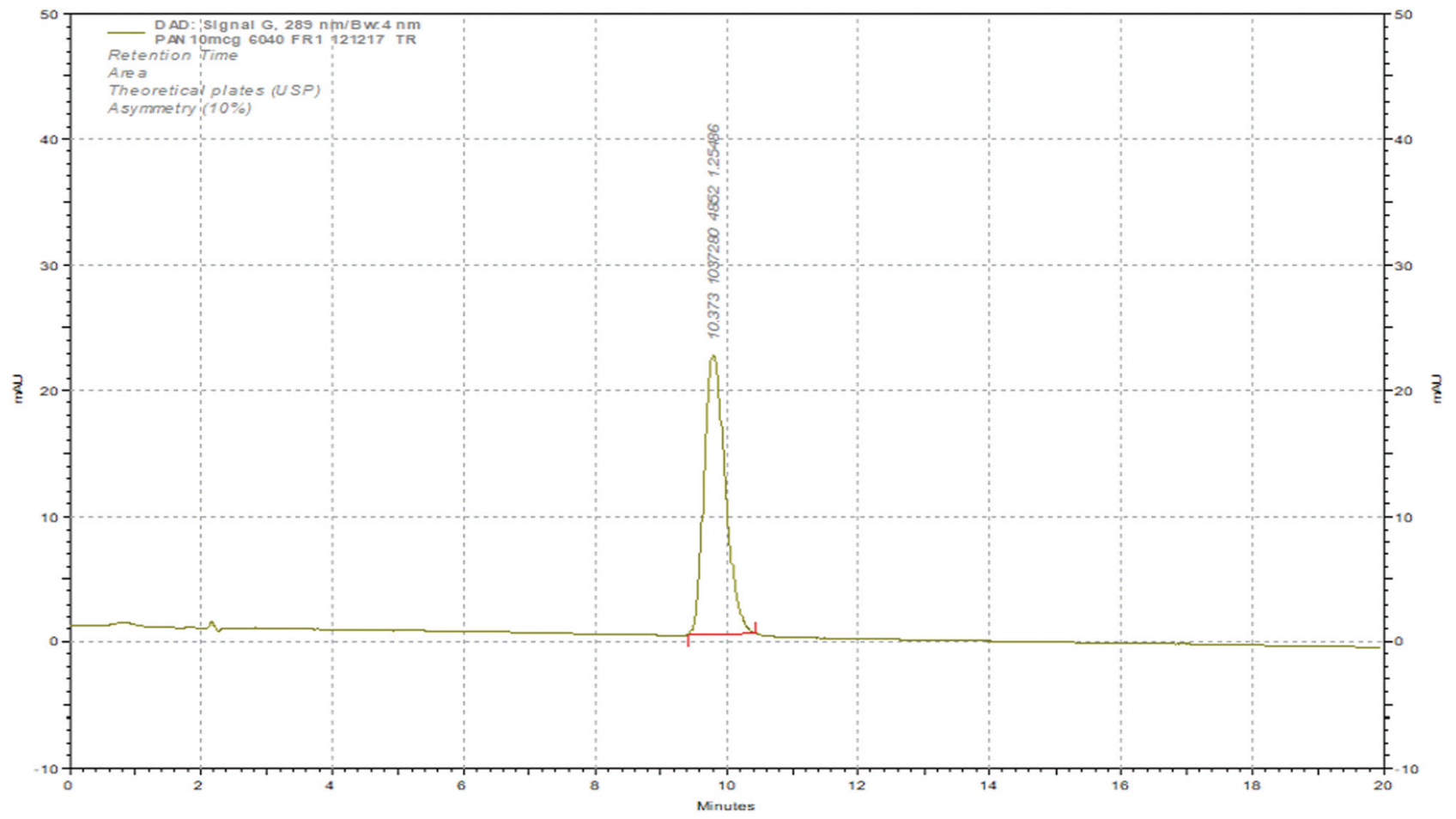

Figure 2. Optimized chromatogram of pantoprazole on $\mathrm{C}_{18}$ column at $290 \mathrm{~nm}$ 
Table 3. Degradation profile of pantoprazole by various stress conditions for oxidative and photolytic degradation by HPLC-DAD

\begin{tabular}{|c|c|c|c|c|c|c|c|c|c|c|c|c|c|c|c|c|c|c|c|c|c|c|}
\hline \multirow[t]{2}{*}{ Stress } & \multirow[t]{2}{*}{ Duration } & \multicolumn{18}{|c|}{ Degradation products } & \multirow[t]{3}{*}{ Total Imp. } & \multirow[t]{3}{*}{ \% Deg. } & \multirow[t]{2}{*}{ Mass balance } \\
\hline & & 1 & 2 & 3 & 4 & 5 & 6 & 7 & 8 & 9 & 10 & 11 & 12 & 13 & 14 & 15 & 16 & 17 & 18 & & & \\
\hline \multicolumn{21}{|c|}{ Oxidative degradation } & & \\
\hline $\mathrm{H}_{2} \mathrm{O}_{2}$ & $24 \mathrm{~h}$ & - & - & Yes & Yes & - & Yes $^{a}$ & - & - & Yes & - & - & - & - & $\mathrm{Yes}^{a}$ & - & - & - & - & 5 & 11.2 & 94.13 \\
\hline AIBN & $24 \mathrm{~h}$ & - & Yes $^{a}$ & Yes & Yes & - & Yes $^{a}$ & Yes & - & - & - & Yes & - & Yes & Yes $^{a}$ & Yes & - & Yes & Yes & 11 & 17.2 & 98.26 \\
\hline $\mathrm{KNO}_{3}$ & $24 \mathrm{~h}$ & - & - & Yes & Yes & Yes & Yes & Yes & Yes & - & Yes & - & - & Yes & - & - & - & - & - & 8 & 7.84 & 96.77 \\
\hline Aerator & $24 \mathrm{~h}$ & - & Yes & Yes & Yes & - & & Yes & - & - & - & - & - & Yes & Yes & - & - & - & - & 5 & 10.8 & 87.75 \\
\hline \multicolumn{23}{|c|}{ Photo degradation } \\
\hline Sun light & $8 \mathrm{~h}$ & - & Yes $^{a}$ & Yes & - & - & - & Yes & Yes & - & - & Yes & - & - & Yes $^{a}$ & Yes & Yes & - & - & 8 & 52.7 & 85.21 \\
\hline UV light & $4 \mathrm{~h}$ & Yes & Yes $^{a}$ & Yes & - & - & Yes $^{a}$ & Yes & - & - & - & - & Yes & - & Yes $^{a}$ & - & - & - & - & 7 & 16.3 & 89.12 \\
\hline Visible & $12 \mathrm{~h}$ & - & - & - & - & - & - & - & - & - & Yes & - & - & - & - & - & - & - & - & 1 & 5.5 & 92.73 \\
\hline$t_{\mathrm{R}}$ & Min & 2.5 & 3.18 & 3.4 & 3.9 & 4.6 & 5.3 & 5.6 & 6.2 & 7.3 & 7.7 & 8.1 & 8.3 & 8.8 & 9.4 & 12.3 & 13.6 & 14.2 & 15.2 & - & - & - \\
\hline
\end{tabular}

agents, namely, hydrogen peroxide $\left(0.3 \% \quad \mathrm{H}_{2} \mathrm{O}_{2}\right)$, azobisisobutyronitrile $(0.3 \%$ AIBN $)$, potassium nitrate $(0.3 \%$ $\left.\mathrm{KNO}_{3}\right)$, and oxygen $\left(\mathrm{O}_{2}\right.$ aeration). For each stress type, stress stock solution for PTZ drug and its PTZ injection formulation $(1000 \mu \mathrm{g} / \mathrm{mL})$ was prepared as described above, with respective oxidizing agents at $0.3 \%$ concentration, except for $\mathrm{O}_{2}$ aeration where $\mathrm{O}_{2}$ was supplied to stock solution by an aerator for a period of $24 \mathrm{~h}$. These solutions were kept at room temperature for oxidative decomposition.

Periodically, the stress sample size of $150 \mu \mathrm{L}$ from the above stress stock solutions was withdrawn and diluted to $10 \mathrm{~mL}$ with the mobile phase $(15 \mu \mathrm{g} / \mathrm{mL})$. The PTZ drug substance sample was analyzed under the optimized chromatographic conditions at different time points $1,4,6,12,18$, and $24 \mathrm{~h}$. The number of degradation products (impurities) was noted based on retention time, and the $\%$ degradation was calculated based on peak areas of the PTZ control and the PTZ stress test sample. The degradation data are given in Table 3. The PTZ injection formulation sample was injected at $24 \mathrm{~h}$. Chromatograms are shown in Figure 3A to 3D.

2.8. Photolytic Stress Degradation. Photolytic degradation studies were carried out by exposing $10 \mathrm{~mL}$ of primary stock solution $(1000 \mu \mathrm{g} / \mathrm{mL})$ of PTZ drug substance and PTZ injection formulation to different types of light, namely, sunlight, UV light, and visible light. The PTZ drug samples were withdrawn periodically, diluted to $15 \mu \mathrm{g} / \mathrm{mL}$, and was analyzed at 0 (control), 1, 2, 3, 4, 8, 12, and $24 \mathrm{~h}$. The UV light used in the study was validated as per the ICHQ1B guidelines. The quinine actinometry method was used to fix the exposure time of light (not less than 1.2 million lux hours or an integrated UV light energy of less than $200 \mathrm{~W} \mathrm{~h} / \mathrm{m}^{2}$ ). The consolidated degradation data is presented in Table 3. The PTZ formulation sample was injected at $4 \mathrm{~h}$ (UV), $12 \mathrm{~h}$ (visible), and $24 \mathrm{~h}$ (sunlight) time points. The results were compared with the PTZ drug substance data. Chromatograms are shown in Figure 4A to 4C.

2.9. Identification of Impurities. Based on the observation from the chromatogram of PTZ injection degradation chromatogram for oxidation at $24 \mathrm{~h}$ and photolysis at 1.2-million-lux-hour exposure, 3 common degradation products of PTZ, such as sulfone derivative of pantoprazole(5(difluoromethoxy)-2-((3,4-dimethoxypyridin-2-yl)methylsulfonyl)$1 H$-benzo $[d]$ imidazole), pantoprazole $N$-oxide (2-(((6(Difluoromethoxy)-1H-benzo[d]imidazol-2-yl)sulfinyl)methyl)3,4-dimethoxypyridine 1-oxide 6-(difluoromethoxy)-2-[(3,4dimethoxy-1-oxidopyridin-1-ium-2-yl)methylsulfinyl]-1H-

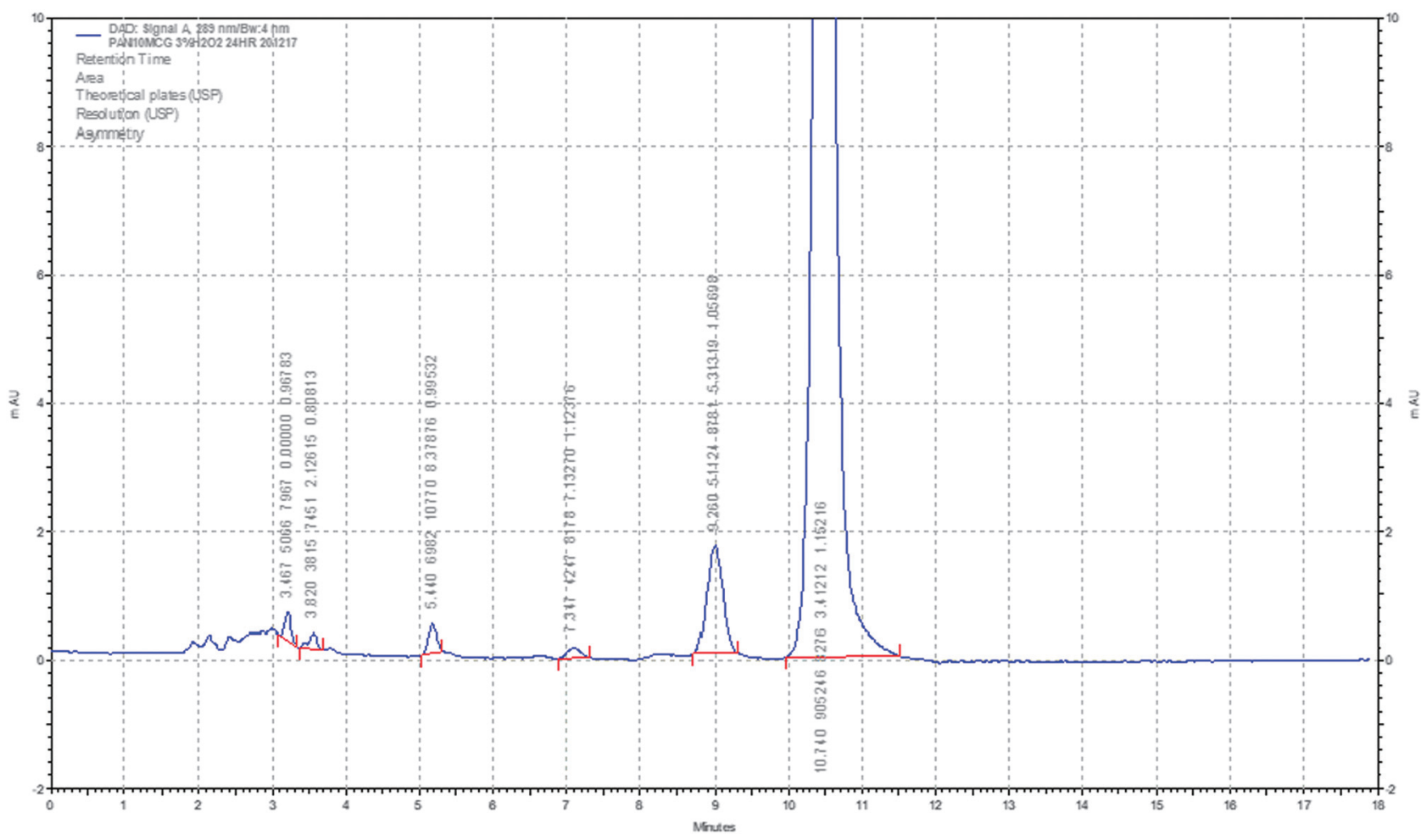

Figure 3A. Chromatogram for oxidative degradation of pantoprazole by $\mathrm{H}_{2} \mathrm{O}_{2}$ at $24 \mathrm{~h}$ 


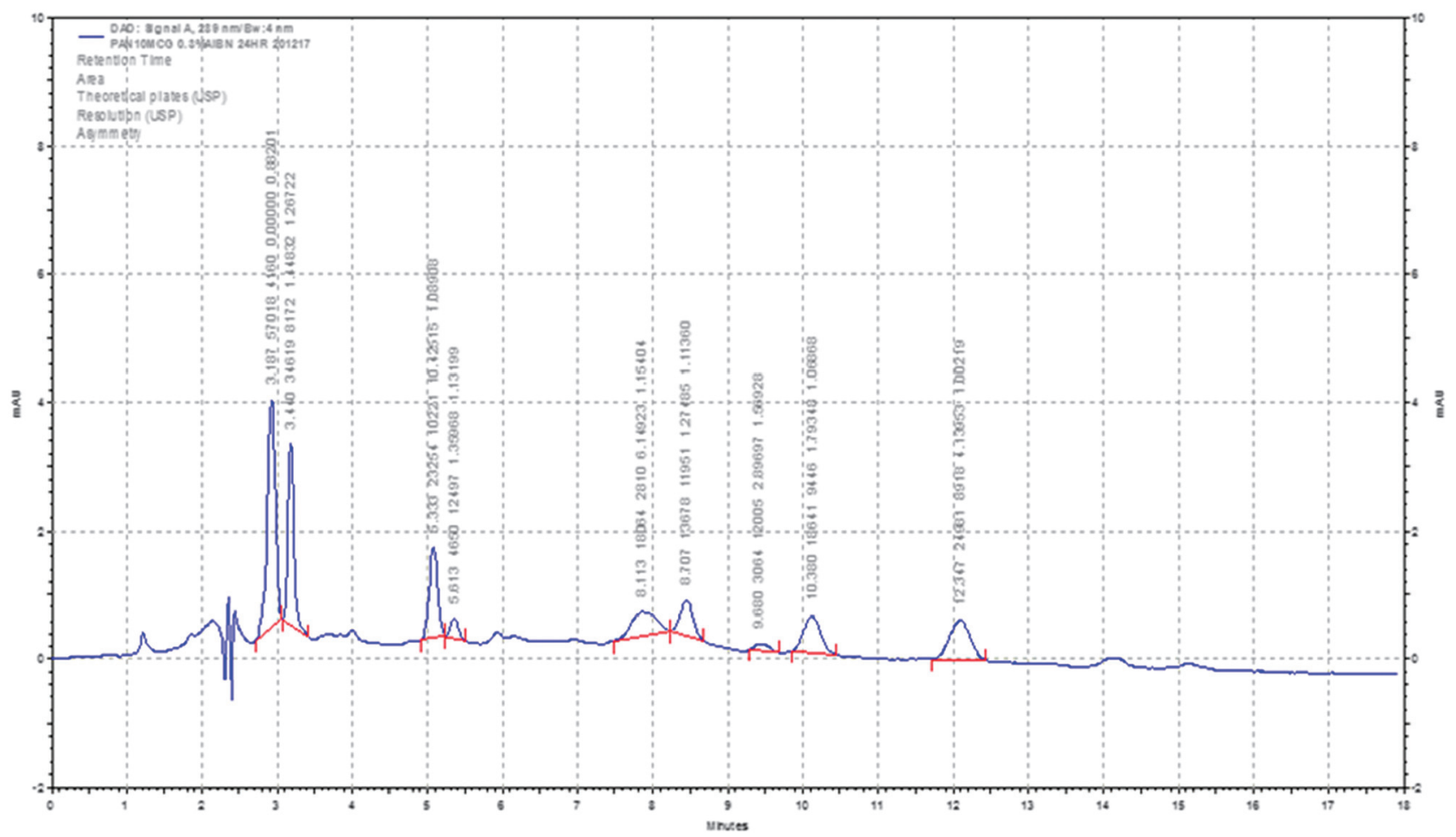

Figure 3B. Chromatogram for oxidative degradation of pantoprazole by AIBN at $24 \mathrm{~h}$

benzimidazole), and $N$-oxide of sulfone derivatives (2(((6-(Difluoromethoxy)-1H-benzo[d]imidazol-2-yl)sulfonyl) methyl)-3,4-dimethoxypyridine 1-oxide 6-(difluoromethoxy)-2[(3,4-dimethoxy-1-oxidopyridin-1-ium-2-yl)methylsulfinyl]-1H- benzimidazole), were identified by a spike method (Figure 1). In this spike procedure, $0.1 \mathrm{~mL}$ of the $1 \mu \mathrm{g} / \mathrm{mL}$ solution of these impurities was added to stress product samples of both photolytic and oxidative degradation. Then, the spiked stress

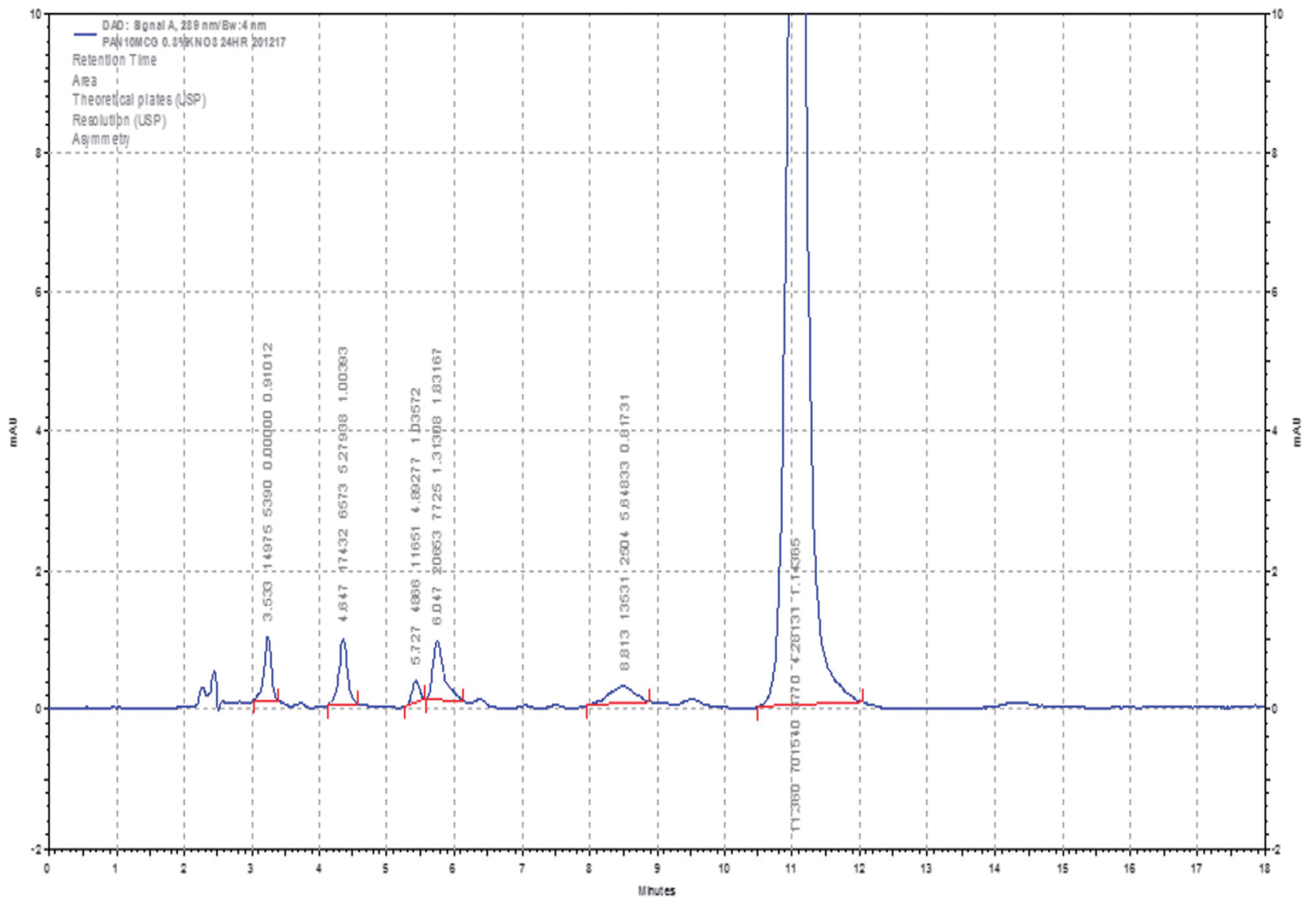

Figure 3C. Chromatogram for oxidative degradation of pantoprazole by $\mathrm{KNO}_{3}$ at $24 \mathrm{~h}$ 


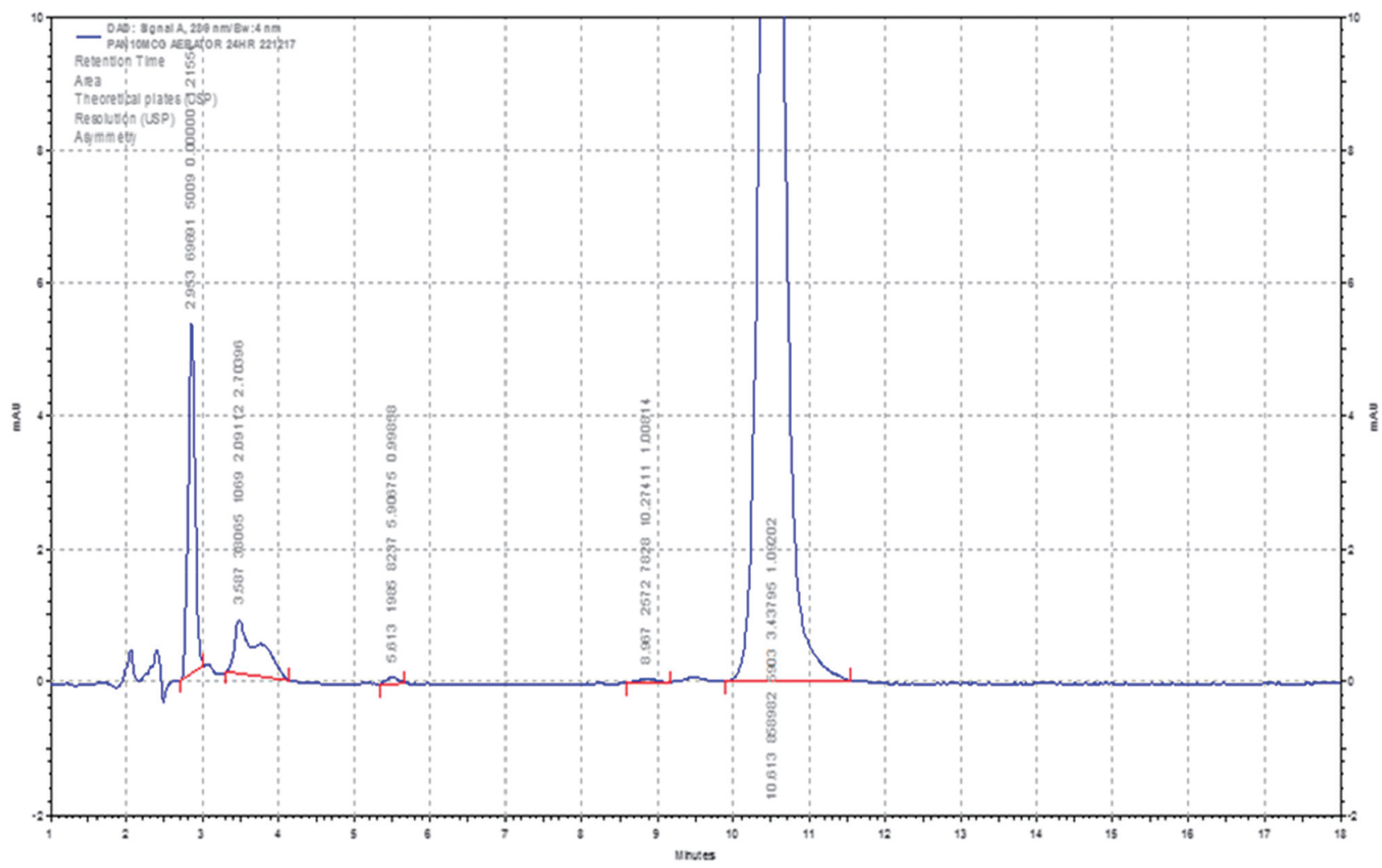

Figure 3D. Chromatogram for oxidative degradation of pantoprazole under oxygen aeration at $24 \mathrm{~h}$

samples were analyzed along with the control stress sample. The peak height of impurity peaks and PDA-UV spectrum of known impurity was used to identify the impurities.

2.10. Method Validation. The developed method was validated as per the ICH Q2 guidelines [2] for various parameters including specificity, linearity, precision, accuracy, limit of detection (LOD), limit of quantification (LOQ), and robustness. Results are shown in Table 4. The LOD and LOQ parameters were included in the validation to demonstrate the method sensitivity.

\section{Results and Discussion}

3.1. Method Optimization. The objectives of this RPHPLC method were to determine PTZ in the presence of its degradation products under various stress conditions with

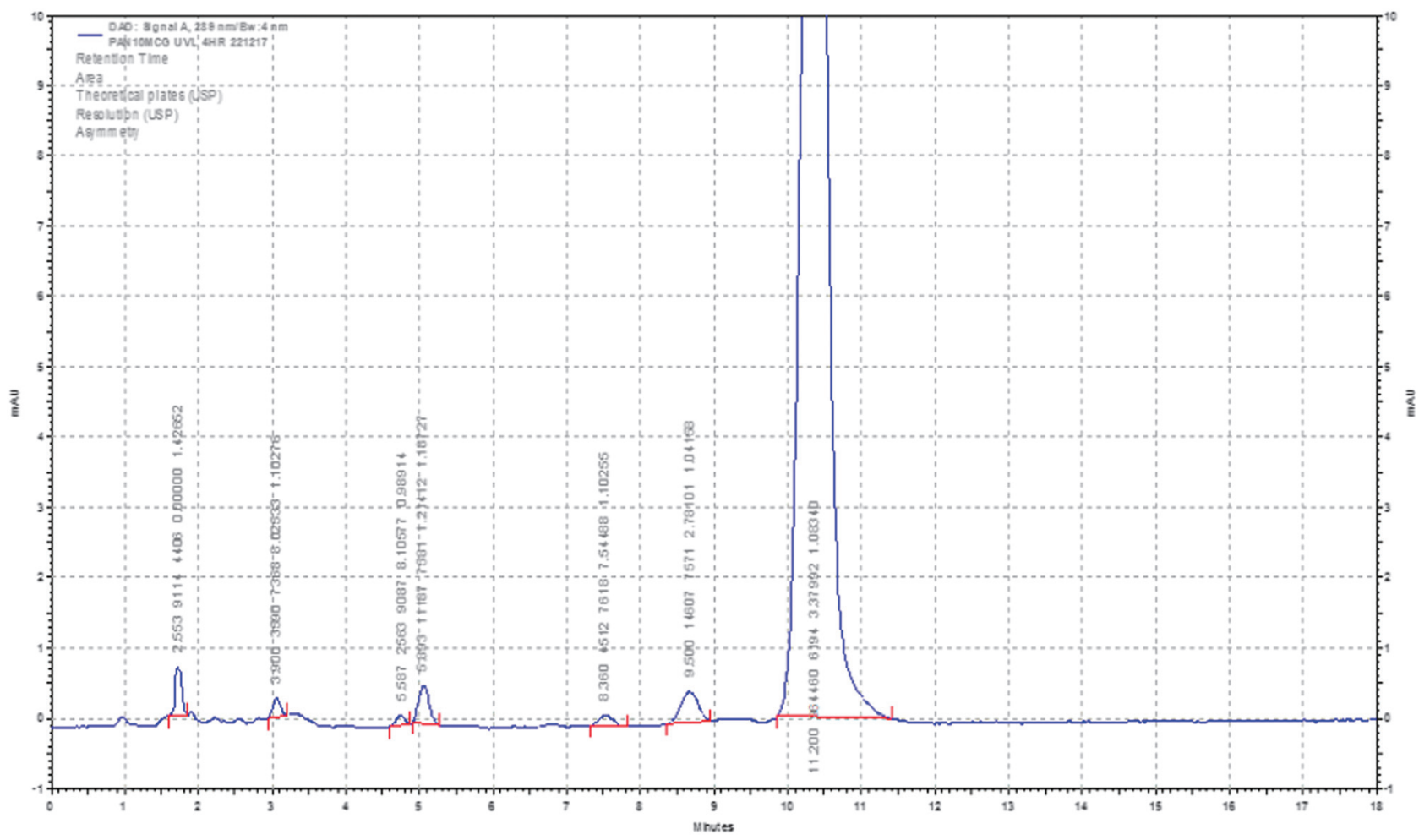

Figure 4A. Chromatogram for photolytic degradation of pantoprazole under sunlight at $12 \mathrm{~h}$ 


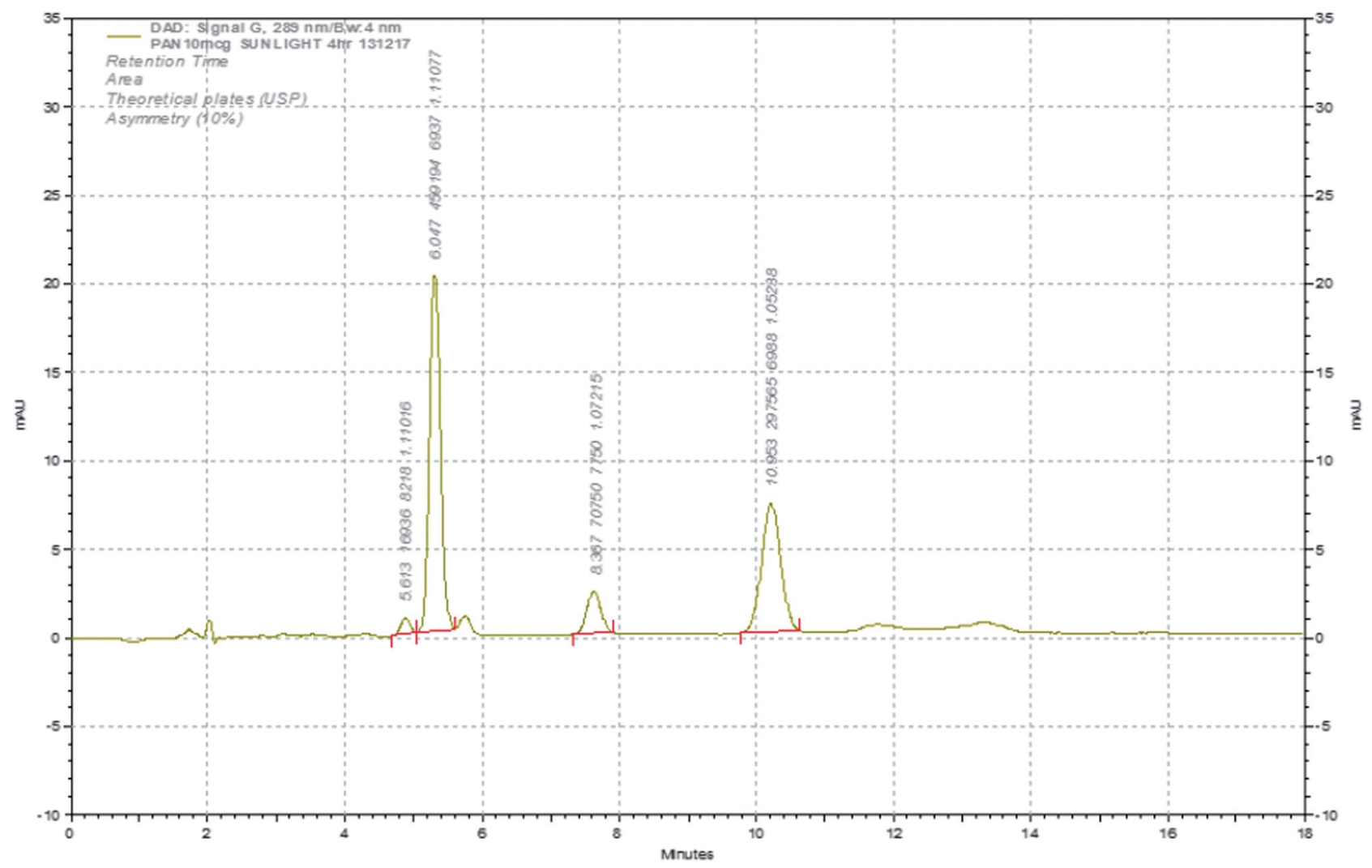

Figure 4B. Chromatogram for photolytic degradation of pantoprazole under UV light at $4 \mathrm{~h}$

acceptable specificity, accuracy, and precision as per the ICH. The chemical structure of PTZ and its common degradation products are shown in Figure 1. The structural features and solubility profile of PTZ satisfied the choice of analytical technique and reversed mode of liquid chromatography. In the method development process, the ODS $\mathrm{C}_{18}$ column was employed as the stationary phase, while diode array detection (DAD) was chosen to monitor PTZ and its degradation product elution in a range of wavelength between 230 and $330 \mathrm{~nm}$, but the PTZ quantification was based on detection at

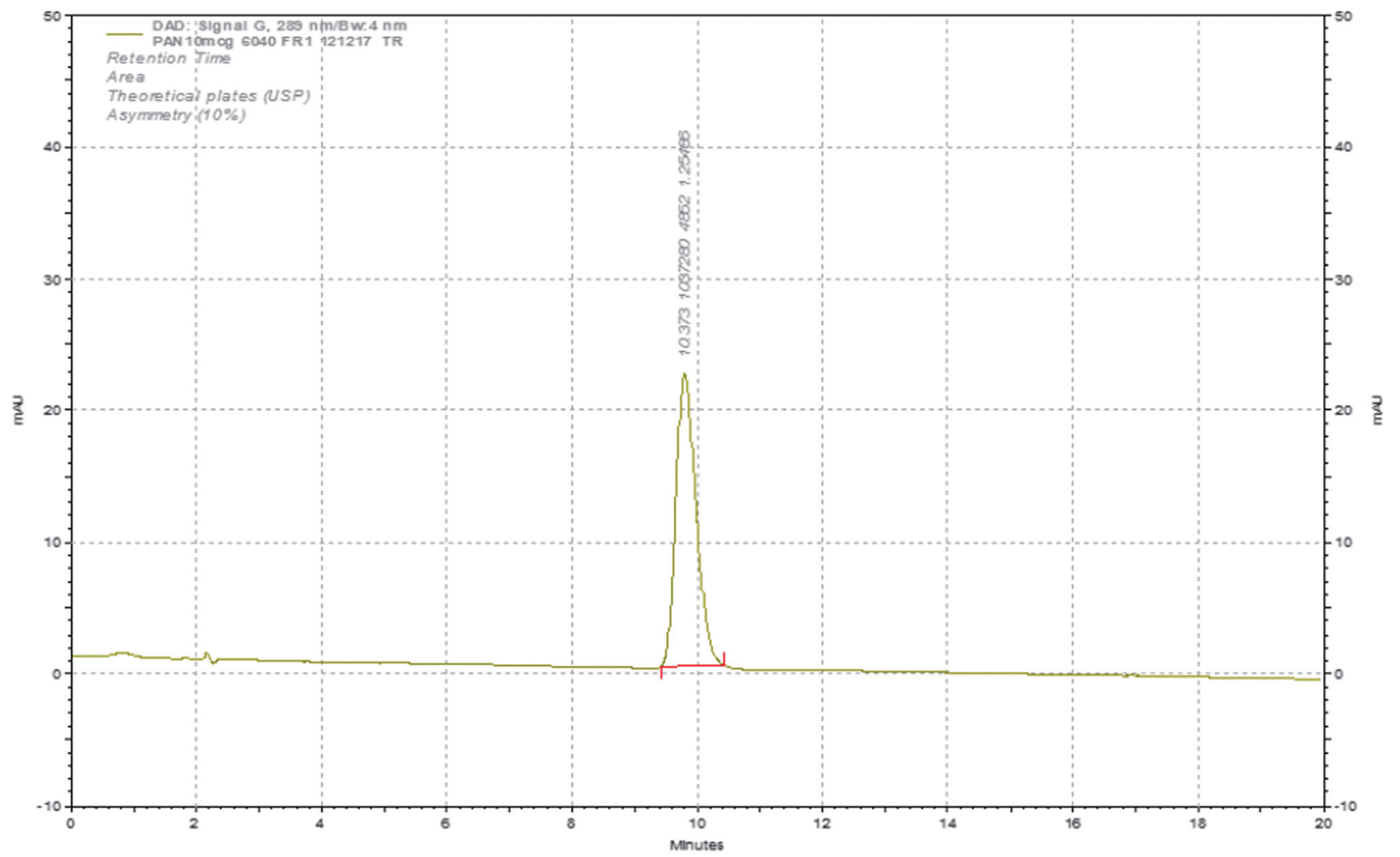

Figure 4C. Chromatogram for photolytic degradation of pantoprazole under a visible lamp at $8 \mathrm{~h}$ 
Table 4. Results of analytical method validation for the developed RPHPLC method for PTZ

\begin{tabular}{lcc}
\hline Parameters & Results & Acceptance criteria \\
\hline Specificity & Pass (Peak purity $>99 \%)$ & No co-elution / Pass \\
Linearity & $5-25 \mu \mathrm{g} / \mathrm{mL}\left(r^{2}: 0.9995\right)$ & $>0.999 /$ Pass \\
Intermediate precision & $10 \mu \mathrm{g} / \mathrm{mL}: 1.11 \%$ (RSD) & $<2 \% /$ Pass \\
& $15 \mu \mathrm{g} / \mathrm{mL}: 1.23 \%$ (RSD) & $<2 \% /$ Pass \\
& $20 \mu \mathrm{g} / \mathrm{mL}: 1.18 \%$ (RSD) & $<2 \% /$ Pass \\
Repeatability (RSD) & $10 \mu \mathrm{g} / \mathrm{mL}: 0.59 \%$ & $<2 \% /$ Pass \\
\multicolumn{1}{c}{$15 \mu \mathrm{g} / \mathrm{mL}: 0.50 \%$} & $<2 \% /$ Pass \\
Accuracy & $20 \mu \mathrm{g} / \mathrm{mL}: 0.49 \%$ & $<2 \% /$ Pass \\
$80 \%$ level & & \\
$100 \%$ level & $98.9 \%$ & $98-102 \% /$ Pass \\
$120 \%$ level & $99.3 \%$ & $98-102 \% /$ Pass \\
LOD & $101.7 \%$ & $98-102 \% /$ Pass \\
LOQ & $0.025 \mu \mathrm{g} / \mathrm{mL}$ & Not defined \\
Robustness & $0.0825 \mu \mathrm{g} / \mathrm{mL}$ & Not defined \\
$\%$ Organic $( \pm 3 \%)$ & $1.22 \%(\mathrm{RSD})$ & $<2 \% /$ Robust \\
pH $( \pm 0.2)$ & $1.69 \%$ (RSD) & $<2 \% /$ Robust \\
Flow rate $( \pm 0.1 \mathrm{~mL})$ & $1.22 \%$ (RSD) & $<2 \% /$ Robust \\
\hline
\end{tabular}

$290 \mathrm{~nm}$. The method optimization trials were performed with a mixture of methanol and water as the mobile phase at increasing contents of aqueous phase, i.e., 80:20, 70:30, $65: 35$, and $60: 40(v / v$; Table 1$)$. The $\mathrm{pH}$ buffering was done at 3.0 and 3.5 with an ortho-phosphoric acid (OPA) buffer. The flow rate was controlled at $1 \mathrm{~mL} / \mathrm{min}$. During this method development stage, we found that there was a persistent increase in the retention of PTZ with the increase in \% aqueous composition. The effect of $\mathrm{pH}$ was negligible on the retention of $\mathrm{PTZ}$, but there was a moderate effect on the tailing of PTZ peak at $\mathrm{pH} 3.5$. Thus, the $\mathrm{pH}$ was reduced to 3.0 to minimize the tailing factor for PTZ peak. The optimized method was tested for stressed samples for resolution $(>2)$ of PTZ from impurities and demonstrated its specificity to PTZ in the presence of all possible degradation products of PTZ. Thus, the optimized condition eluted the PTZ at $10.3 \pm 0.1 \mathrm{~min}$ with acceptable system suitability parameters as shown in Figure 2 and Table 2. The resolution between PTZ and other impurities was more than 2, and the peak purity was more than $99 \%$. Thus, the method was optimized to use in the stress degradation study of PTZ under various stress conditions. Finally, this method was validated as per the ICH Q2 guidelines (ICH, 2003).

3.2. Oxidative Degradation Studies. Oxidative degradation of PTZ drug substance and its injection powder formulation was performed using 4 stress conditions such as $0.3 \% \mathrm{H}_{2} \mathrm{O}_{2}, 0.3 \% \mathrm{AIBN}, 0.3 \% \mathrm{KNO}_{3}$, and $\mathrm{O}_{2}$ aeration in the solution state. After $24 \mathrm{~h}$ of stress period, 15 impurities were recorded in oxidative degradation of the PTZ drug substance. In detail, PTZ recorded 11 impurities with AIBN stress and 5 impurities with hydrogen peroxide stress. The potassium nitrate degraded the PTZ to produce 8 impurities. The $\%$ degradation of PTZ for AIBN stress was $17.2 \%$ and $11.2 \%$ for $\mathrm{H}_{2} \mathrm{O}_{2}$, stress. The AIBN degraded the PTZ relatively more as compared to other stress conditions. Comparing the effect of potassium nitrate with oxygen aeration, potassium nitrate induced more impurities than oxygen supply; nevertheless, the $\%$ degradation was in a reverse phenomenon. Among all stress conditions, 2 common impurities were found, i.e., impurity 3 (3.4 $\mathrm{min})$ and impurity 4 (3.9 $\mathrm{min})$. There are many stress reagent specific impurities formed; they are impurity 9 (for hydrogen peroxide) as observed in Figure 3A, impurity $11,15,17,18$ (for AIBN) as in Figure 3B, and impurity 5 and 10 (for potassium nitrate) as in Figure 3C. Impurities produced after $24 \mathrm{~h}$ of oxygen aeration is shown in Figure 3D. The retention time of each impurity is shown in Table 3. At $24 \mathrm{~h}, \mathrm{PTZ}$ injection stressed sample showed the impurities in peroxide (impurity 6 and 14) and AIBN (impurity 2, 6, and 14) stressed samples. The other stress agents $\mathrm{KNO} 3$ and oxygen aeration did not produce any impurities in the PTZ injection formulation at $24 \mathrm{~h}$.

3.3. Photolytic Degradation. The photolytic degradation of PTZ drug substance and its injection powder formulation was carried out using sunlight, UV, and visible light in solution state. The percentage of degradation and impurity data were compiled at 1.2 million lux hours of light exposure. For PTZ drug substance, the comparative data showed the formation of 11 degradation products. Among the stress conditions employed, UV light produced more impurities (8 degradation products), then followed by sunlight ( 7 degradation products) at 1.2 million-lux-hour exposure duration. The visible light irradiation showed only one impurity (at $12 \mathrm{~h}$ ). Interestingly, there are only 4 degradation products (impurity 2, 3, 7, and 14), which were common between sunlight ( $8 \mathrm{~h}$ ) and UV light exposure $(4 \mathrm{~h})$; further, it was noted that sunlight produced the highest degradation of $52.7 \%$ compared to the UV light exposure (16.2\%). The degradation products, impurity 8 (6.2 $\mathrm{min})$, impurity 11 (8.1 $\mathrm{min})$, impurity 15 (12.3 $\mathrm{min})$, and impurity 16 (13.6 min) are sunlight specific, as shown in Figure 4B, whereas, impurity $1(2.5 \mathrm{~min})$, impurity 6 (5.3 $\mathrm{min})$, and impurity 12 (8.3) are UV-light specific, as shown in Figure 4A. The impurity produced by visible light at 7.7 min (impurity 10), shown in Figure 4C, was similar to the oxidation product produced in potassium nitrate stress. The detailed degradation data including mass balances are presented in Table 3. At the end of the 1.2 million-hour exposure, PTZ injection stressed sample produced impurities in sunlight (impurity 2 and 14) and UV light (impurity 2, 6, and 14) stressed samples, whilst the visible light irradiation did not induce degradation.

3.4. Identification of Impurities. Table 3 shows that there are 3 degradation products (impurity 1, 12, and 16) specific to photolysis and 6 degradation products (impurity 4, 5, 9, 13, 17, and 18) specific to oxidation. We noted that there was a significant difference in the \% degradation and number of impurities formed in different stresses employed. Based on the information obtained from the degradation data of PTZ and its PTZ injections, there were 3 impurities of drug products, namely, sulfone derivative of pantoprazole (impurity 14 at $9.4 \mathrm{~min}$ ), pantoprazole $N$-oxide (impurity 6 at $5.3 \mathrm{~min}$ ), and $\mathrm{N}$-oxide of sulfone derivatives (impurity 2 at $3.1 \mathrm{~min}$ ) identified by a spike method. These impurities were added to the stress sample at $1 \mu \mathrm{g} / \mathrm{mL}$ concentration. The identified impurities were common in both photolytic and oxidative degradation. It was noted that $N$-oxide of sulfone derivatives (impurity 2 at $3.1 \mathrm{~min}$ ) was found only with AIBN-induced oxidation but not with hydrogen peroxide at the 24th hour. The pantoprazole $N$-oxide was found with UV light exposure but not with sunlight exposure. It was observed that the above three impurities were detected in pantoprazole injection formulation under the same stress conditions. The reason for the low level of impurities may be due to its sodium salt form, which has already supported by the report by Ronald F Donnelly [19]. Thus, our study concurs the earlier [19] report that sodium salt of pantoprazole reduced the susceptibility of pantoprazole from intense degradation.

3.5. Validation of the Method. The developed RP-HPLC method was validated for all validation parameters as per the ICH Q2 guidelines, including specificity, linearity, repeatability, intermediate precision, accuracy, the limit of detection, the limit of quantification, and robustness test. The PTZ solution of $15 \mu \mathrm{g} / \mathrm{mL}$ was used throughout the method validation to ensure the system suitability (SST). The specificity of the method was verified by using stress sample 
analyses. The method was found to be specific for PTZ with a resolution of more than 2 from impurity 14 and impurity 15 . Further, the DAD signal at $290 \mathrm{~nm}$ showed an acceptable peak purity of $>99 \%$ and satisfied the purity threshold and purity angle criteria. The linearity of the method was tested for the concentration range from 5 to $25 \mu \mathrm{g} / \mathrm{mL}$. The value of correlation coefficient $\left(r^{2}\right)$ was $0.9995(y=69,489 x+20,257)$, indicating the acceptable quantification limit. Precision and accuracy were studied at $15 \mu \mathrm{g} / \mathrm{mL}$. The $\% R S D$ values for repeatability ( $n=9$; intra-day precision) and intermediate precision $(n=3$; inter-day precision) were $<0.6 \%$ and $<1.5 \%$, respectively. This indicated that the method was highly precise. The accuracy of the method was tested by a recovery study at $80 \%, 100 \%$, and $120 \%$ levels using a placebo mixture and PTZ injection formulation. The respective \% accuracy values for these levels were $98.9 \%$, $99.3 \%$, and $101.7 \%$. Thus, concerning the acceptance criteria (Table 4), the developed method was highly accurate and precise. As per the ICHQ2, though the LOD and LOQ parameters are not needed for assay procedure, the respective values were still calculated to assess the sensitivity of the method, and it was found that the LOD of $0.25 \mu \mathrm{g} / \mathrm{mL}$ and the LOQ of $0.825 \mu \mathrm{g} / \mathrm{mL}$ indicated high method sensitivity. The robustness of the developed method was tested for 3 critical method parameters, such as a change in flow rate $( \pm 0.1 \mathrm{~mL} / \mathrm{min})$, mobile phase composition $( \pm 2 \%)$, and $\mathrm{pH}$ $( \pm 0.2)$. The retention time and peak area were used method responses to assess the robustness of the method. Robustness tests revealed that the method was robust for the entire tested method variable within the test range. It was noted that the effect of $\mathrm{pH}$ on method precision was considerably affected by the increased $\% R S D$ to $1.69 \%$ for precision (should be less than $2 \%$ ), but the retention time was less affected. This indicated that the $\mathrm{pH}$ of the mobile phase should be considered as the most important method variable while performing analysis for PTZ. Overall, the developed method passed the validation criteria as per the ICHQ2 guidelines.

\section{Conclusion}

The developed method has demonstrated a total of $18 \mathrm{impu}-$ rities as degradation products of pantoprazole under various stress inducers belonging to oxidative and photolytic degradations. It was concluded that there are significant differences observed in \% degradation and the number of impurities formed in different stress conditions employed. Thus, 3 degradation products (impurity 1, 12, and 16) can be concluded as specific to photolysis, whereas 6 degradation products (impurity $4,5,9,13,17$, and 18) were specific to oxidation. The other identified impurities were common impurities of both photolytic and oxidative degradation. Three impurities of drug products, namely, sulfone derivative of pantoprazole (impurity 14 at $9.4 \mathrm{~min}$ ), pantoprazole $\mathrm{N}$-oxide (impurity 6 at $5.3 \mathrm{~min}$ ), and $\mathrm{N}$-oxide of sulfone derivatives (impurity 2 at $3.1 \mathrm{~min}$ ), were detected.

\section{Conflict of Interest}

Authors convey no conflict of interest.

Acknowledgments. The authors wish to thank Walksman Salesman Pharmaceutical Private Limited, Anantapur for providing the pantoprazole gift sample for this study. Authors are thankful to Ms. Mounika Bai for support in DST-FIST facility of Raghavendra Institute of Pharmaceutical Education and Research, Anantapur, AP, India.

\section{References}

1. FDA Guidance for Industry, INDs for Phase II and III Studies Chemistry, Manufacturing, and Controls Information, Food and Drug Administration, Available from: 2003.

2. International Conference on Harmonization, ICH Q2 Guidelines, Available from: http://www.fda.gov/downloads/RegulatoryInformation/ Guidances/ucm128204.pdf, 2003.

3. Reynolds, D. W.; Facchine, K. L.; Mullaney, J. F. Pharm. Technol. 2002, 26, 48 .

4. Brummer, H. Life Sci. Technol. Bull. 2011, 1, 1

5. Gupta, K. R.; Chawla, R. B.; Wadodkar, S. G. Orbital: Electron. J. Chem. 2010, 2, 181.

6. Wahbi, A. M.; Abde Razak, O.; Gazy, A. A.; Mahgoub, A.; Moneeb, M. S. J. Pharm. Biomed. Anal. 2002, 30, 1133.

7. Syed, A.; Syeda, A. Indian J. Pharm. Sci. 2008, 70, 507.

8. Prasanna, R. B.; Kirankumar, R. N. Int. J. ChemTech Res. 2009, 1, 195. 9. Letica, J.; Markovic Zirojevic, S. J.; Nikolic, K.; Agbaba, D. J. AOAC Int. 2010, 93, 1121 .

10. Ramakrishna, N. V. S.; Vishwottam, K. N.; Wishu, S.; Koteshwara, M. J. Chromatogr. B: Anal. Technol. Biomed. Life Sci. 2005, 822, 326.

11. Li, Y.; Ding, M. J.; Ma, J.; Wang, S.; Wu, X. L.; Xu, H. J.; Lu, Z. Y.; Zou, J. J.; Fan, H. W.; Zhou, X. M. Eur. J. Drug Metab. Pharmacokinet. 2011, $35,147$.

12. Dotsikas, Y.; Apostolou, C.; Soumelas, S.; Kolocouri, F.; Ziaka, A.; Kousoulos, C.; Loukas, Y. L. J. AOAC Int. 2010, 93, 1129.

13. Challa, B. R.; Boddu, B. R.; Awen, B. Z.; Chandu, B. R.; Bannoth, C. K.; Khagga, M.; Kanala, K.; Shaik, R. J. Chromatogr. B: Anal. Technol. Biomed. Life Sci. 2010, 878, 1499.

14. Patel, B. H.; Suhagia, B. N.; Patel, M. M.; Patel, J. R. J. AOAC Int. 2007, 90, 142 .

15. Deepak Bageshwar, V.; Khanvilkar, V. K. J. Pharm. Anal. 2011, 1, 275.

16. Radi, A. J. Pharm. Biomed. Anal. 2003, 33, 687.

17. Krishna, R. G.; Rajesh, B. C.; Sudhir, G. W. Orbital: Electron. J. Chem. 2010, 2, 209.

18. Reddy, G. M.; Bhaskar, B. V.; Reddy, P. P.; Ashok, S.; Sudhakar, P.; Babu, J. M.; Vyas, K.; Mukkanti, K. J. Pharm. Biomed. Anal. 2007, 45, 201.

19. Ronald, F. D.; Can. J. Hosp. Pharm. 2011, 64, 192.

20. Walker, S.; Iazzetta, J.; Law, S. Can. J. Hosp. Pharm. 2009, 62,135.

21. Walker, S. E.; Iazzetta, J.; Law, S. Can. J. Hosp. Pharm. 2005, 58 , S34.

22. Carpenter, J. F.; McNulty, M. A.; Dusci, L. J.; Ilett, K. F. J. Pharm. Technol. 2006, 22, 95.

23. Johnson, C. E. Am. J. Health-Syst. Pharm. 2005, 62, 2410. 